\title{
Modern İlişkilerin Karanlık Veçheleri: The Lobster Filminde Romantik İdeoloji
}

\author{
DOI: 10.26466/opus. 807052 \\ *
}

\author{
Selen Gökçem Akyıldız \\ * Dr. Öğr. Üyesi, Niğde Ömer Halisdemir Üniversitesi, İletişim Fakültesi, Niğde/Türkiye \\ E-Posta: gkselen@gmail.com \\ ORCID: $0000-0002-7948-8330$
}

\section{Öz}

Tarih boyu çeşitli şekillerde teorileştirilmiş aşk kavramı, insan hayatındaki en cazip itici güçlerden olmasina karşın, psişik, ölçülemeyen ve asi bir konu, sanat, edebiyat ve felsefe tarafindan öngörülen bir alan, diğer bir deyişle bilim alanına pek alınmak istenmeyen ancak zevk unsuru olarak üzerinde günden güne daha fazla durulmaya başlanan bir alan olarak görülmüştür. On ikinci yüzyılda bugün üzerine konuştuğumuz aşk kavramı şekillenmeye, takip eden yüzyıllarda toplumsal, kültürel ve özellikle ideolojik yaptlanmalarla birlikte evrilerek de farklı anlamlar ihtiva etmeye başlamıştır. Tüm aşk ideolojilerinin çıkış noktası sayılabilecek Aristophanes efsanesinin her bireyin diğer yarısın araması ve bulduğunda tamamlanacak olması üzerinden şekillenmesi geleneksel romantik ideolojiler arasında yerini almış, romantik aşkın kültürel algısın derinden etkileyerek aşk duygusunun özgürce deneyimlenememesi üzerinde etkili olmuştur. Bu çalışma, Lanthimos'un yönettiği Lobster filmi üzerinden aşkın insanlarm tercihine bırakllmamasının insanların duygularından çok daha önemli olduğu bir dünyada aşk ideolojilerinin nasıl absürtleştiğini distopik bir evrende irdelemeye çalıştı̆̆ noktalara odaklanmaktadır. Doğal olan insan duygularım doğal olmayan ortamlar yaratarak sorgulamaya çalışan The Lobster filmi sonuç olarak değişen romantizm ve aile politikaları karşısında çeşitli anlamlandırma süreçlerinden geçen aşk kavramının yirmi birinci yüzyılda da farklı ideolojik yapılanmalar ile değişip dönüşmeye devam ettiğinin altın çizmektedir.

Anahtar Kelimeler: Sinema, Romantik ideoloji, Lanthimos, Aşk kavramı 


\title{
The Dark Aspects of Modern Relationships: Romantic Ideology in The Lobster
}

\begin{abstract}
Although the concept of love, which has been theorized in various ways throughout history, is one of the most attractive driving forces in human life, it has been seen as a psychic, unmeasurable and rebellious subject, a field envisioned by art, literature and philosophy, in other words, a field that is undesirable to be taken into the field of science, but an element of pleasure that has started to be emphasized day by day. The concept of love, which we are talking about today, took shape in the twelfth century, and evolved with social, cultural and especially ideological structures in the following centuries and started to contain different meanings. The Aristophanes legend, which can be regarded as the starting point of all ideologies of love, has taken its place among traditional romantic ideologies, based on the fact that each individual search for the other half and will be completed when they find them and by deeply affecting the cultural perception of romantic love, it has had an effect on the inability to experience the feeling of love freely. This study focuses on the points where the director Lanthimos tries to examine in The Lobster how love ideologies become absurd in a world where not leaving love to the preference of people is much more important than people's emotions. The Lobster movie, which tries to question natural human emotions by creating unnatural environments, underlines that the concept of love, which has gone through various interpretation processes in the face of changing romance and family politics, continues to change and transform with different ideological structures in the twenty-first century.
\end{abstract}

Keywords: Cinema, Romantic ideology, Lanthimos, Concept of love. 


\section{Giriş}

Aşk, bir toplumsal eylem olarak ele alındığından toplumsal yapının bir unsuru olarak analiz edilir. Romantik karmaşıklık nadir olmakla birlikte, çoğu toplumlarda bir "aşk düzeni" bulunur. Aşk, gelecek nesilleri ve sınıf katmanlarını potansiyel olarak yıkma tehlikesi içerdiğinden kontrol edilmelidir ve bu nedenle, farklı sosyal yapılarda anlamı farklı olduğu için çeşitli tedbirlerle kontrol edilir. Aşk tek başına bir eylemin ya da kararın unsuru haline gelebilecek potansiyele sahiptir. Buna rağmen aşk üzerine kapsamlı ve ciddi sosyolojik çalışmalar nadir olarak yapılmıştır. Yapılan çalışmalar da genellikle Batı dünyasında eş seçimi ile sınırlandırılmış ve aşkın yapısal önemi çoğunlukla göz ardı edilmiştir. Güçlü aşk bağları herhangi bir toplumda meydana gelebileceğinden ve aşk genellikle evliliğin temeli ve başlangıcı sayıldığından, bir şekilde kontrol edilmeli veya bildik bir yöne doğru kanalize edilmelidir. Diğer bir deyişle, aşkın potansiyel olarak yıkıcı etkileri kontrol altında tutulmazsa, tabakalaşma ve soy desenleri büyük ölçüde zayıflayacaktır. Goode'a (1959, s.39) göre bu zayıflamayı önleyecek en önemli kurum da ailedir. Hem çocuğun sosyal yapıya yerleşimi hem de eş seçimi sosyal açıdan önemlidir çünkü hem yerleştirme hem de seçim iki akrabalık hattını birbirine bağlar. Dolayısıyla, sevgili veya eş seçimi aile veya toplum tarafından göz ardı edilemez. Rastgele çiftleşmeye izin vermek, mevcut sosyal yapıdaki radikal değişim anlamına gelir. Toplumun bir birimi olarak aile önemliyse, eş seçimi de önemlidir. Bu nedenle âşıł gençleri uygun rol davranışına itmek için önemli miktarda enerji ve kaynak gerekli olabileceğinden, gençler arasında yaşanacak aşk ortaya çıkmadan önce kontrol edilmelidir. Aşk ilişkileri ya az sayıda tutulmalı ya da onaylanmış akrabalık bağlantılarına ters düşmeyecek şekilde yönlendirilmelidir. Aşk toplum ve kurumlar tarafından kontrolü bir şekilde yaşanırsa hissedilmesine izin verilen bir duygu haline gelir.

Parsons (1951) tarafından da belirtildiği gibi, insan ilişkisini düzenleyen geleneksel kurallar, bu değişikliklerin bilincindeki resmi, rasyonelyasal mekanizmalarla yavaş yavaş yer değiştirmiştir. Önceki dönemlerde var olmayan veya sorunlu görülmeyen davranışları ve ilişkileri yönetmek için yasalar tasarlanmıştır. Dahası çağımızda vatandaşların davranışlarına ilgi gösteren yalnızca devlet değildir. Hukuki sorumluluk 
kavramının genişlemesi, işverenlerin ve meslek birliklerinin işyeri kuralları ve katı mesleki etik kodları aracılığıyla çalışanların veya üyelerin davranışlarını kontrol etmeye çalışmasına neden olmuştur. Bunun sebebi arkadaşlar, komşular ve yakın ilişkiler arasındaki günlük yaşamın özel alanındaki davranışını kültürel normların, halkın ve inançların yönettiği düşüncesine olan inançtır (Dowd ve Palotta, 2000, s.550). Bu tür kültürel haritaların belirgin eksikliği, Fein (1995) ve Schneider'in (1997) hazırladığ1 flört ve romantizm hakkındaki kullanım kılavuzlarının popülerliğini açıklamaya yardımcı olabilir. Bu kılavuzlar, güncel aşk ilişkilerinin mevcut kargaşasına düzen getirmek için tasarlanmış kurallar sağlar. Yazarlar tarafından sunulan kararlar arasında Kural No. 2 ("Bir erkekle önce sen konuşma") ve çok önemli No 5 ("Onu arama ve nadiren çağrılarına geri dön) bulunmaktadır. Erkekler için de yazılmış ve topluma nüfuz eden yazılı kurallar arasında unutulmaya yüz tutmuş eski ve yıkıcı eril kuralların yeniden yaşatılmasına duyulan ihtiyaç vardır.

Aşkın uygun görülen eşleşmeler dışında yaşanması, kural bozuculuğu ve toplumsal normları değiştirici yapısı nedeni ile ilişki içerisinde ancak kontrollü bir şekilde var olmasına izin verecek bir sistemin yüzyıllardır yıkılıp tekrar yapılandırıldığı bir sürecin son ayağı olarak okunabilecek aşırılıklarla dolu distopik film The Lobster, zamansız bir geleceğin ardına gizlenen ancak bugünün dünyasında kurallarla çevrili, organik yapısını kaybetmiş, siyah ve beyazdan ibaret bir dünyayı resmetmektedir. The Lobster filmi, aşkın modern dünyada geldiği noktayı ve ulaşması ancak peri masallarına inanılırsa gerçekleşecek kurallarla dolu aşk duygusuna yüklenmeye çalışılan genel geçer kurallar bütünün insanları nasıl mutsuz bir çımaza sürüklediği noktasına vurgu yapmaktadir.

\section{Yöntem}

Çalışmanın amacı Lanthimos'un The Lobster isimli filmini romantik ideoloji bağlamında aşk kavramı üzerinden incelemektir. Toplumsal normlar çerçevesinde yaşanmadığı ve kontrol altında tutulmadığı takdirde düzen bozucu kabul edilen aşkın, filmde yaratılan birbirine zıt iki dünya düzeninde nasıl işlendiği içerik analizi yöntemi ile ele alınmıştır. Yazılı, sözlü veya görsel dokümantasyonu sistematik olarak 
analiz etmek için niteliksel veya niceliksel olarak kullanılabilen bir yöntem olan içerik analizi (White ve Marsh, 2006, s.22), geçerli ve tekrarlanabilir bir çıkarım yapmak için metni kodlamayı ve yorumlama adına kullanmayı hedefler (Cole, 1988). Bu çalışmada içerik analizi, film dili üzerinden toplanan veriyi açıklayabilecek kavramlara ve ilişkilere ulaşmak adına kullanılmıştır.

\section{Aşkın Modern Tanımı}

Tarihsel olarak, çeşitli şekillerde teorileştirilmiş bir kavram olan aşk, Avrupa'da değişen romantizm ve aile politikaları karşısında çeşitli anlamlandırma süreçlerinden geçmiştir. İnsan hayatındaki en cazip itici güçlerden biri (Irigaray, 1993) olan aşk, psişik, ölçülemeyen ve asi bir konu, sanat, edebiyat ve felsefe tarafından öngörülen diğer bir deyişle bilim alanına pek alınmak istenmeyen ancak zevk unsuru olarak üzerinde günden güne daha fazla durulmaya başlayan bir alan olarak görülmüştür. Erken Avrupa aile tarihi, çeşitli geleneklere dayanan aşk yasalarının çelişkili ve politik olarak tutarsız anlamlarını geliştirirken, aşkın sosyal alanda güvenlik kaynağı olarak yer etmeye başlamasına yardımcı olmuştur.

On dokuzuncu ve yirminci yüzyılın başlarında Avrupa orta ve üst sınıf sosyalizminde aşk, bireysel arzulara ve varoluşsal doğanın kaygılarına karşı narsistik, kendiliğinden bir yönelim olarak ortaya çıkar (Kierkegaard 1847, Heidegger 1927, Freud 1953-74). Freud sonrası cinsellik üzerine düşünmeyi takiben, en etkili toplumsal teoriler, aşkı hem özlemin bireyselleştirilmiş bir şekilde yerine getirilmesi hem de siyasi iktidarın elindeki ticarileştirilmiş bir değer olarak kavramsallaştırır. Böyle karmaşık, ancak karşılıklı olarak münhasır olmayan aşk algısı, biyo-sosyal güçler karşısında bireylerin savunmasızlığının altını çizerken, bağlanma hem çekirdek heteroseksüellik (Buttler, 1997) ahlakına bağlı kalır hem de etkilerinin metalaşması ile daha da korunur bir hale gelir (Illouz, 2007).

Yirminci yüzyılın ikinci yarısında giderek daha çok kültürlü ve eşit derecede bireyci romantizm fikirleri, dini ve ahlaki geleneklerin yerini alan özgürlük, seçim ve rasyonellik temelinde ortaya çıkmaya başlar (Giddens 1992). Bu düşüncenin ardından bireyler, ölüme karşı duran 
zihinsel / erotik bir güç olan Freudcu libido ile örtüşen birçok yaşam tarzı arasından seçim yapabilirler. Çağdaş aşk, bu tür ontolojik tekillikler üzerine düşünür (Szachowicz-Sempruch, 2015). Mutluluğun, arzunun ve bakımın bireysel olarak tanınmasına dayanan bu tekillik, aslında bireyleri öznel olarak güçlendiren veya güçsüzleştiren varoluşsal güvenliğin tek kaynağı olmaya devam eder. Bu şekilde aile yaşamının anahtarı sanki iki uyumsuz alan arasında 'bir denge kurmak' gibi özel ve sosyal birçok önemli yoldan geçip örtüşmemiştir gibi görünür (Lynch 2009).

Eva Illouz (1997) romantik aşkı modernitenin kültürel çekirdeği olarak tanımlar: Aşk, öz değeri ölçmenin bir yolu, kişinin değerinin algılanması ve oluşturulması, uzun etkileşim ritüellerinin zincirindeki merkezi halkadır. Ancak aşk arayışı, uzun bir yoldur, inilti ve acıyla doludur. Why Love Hurts (2012) kitabında Illouz aşkın neden acıttığ1 sorusuna sosyolojik bir açıdan yaklaşmaya çalışmaktadır. Illouz'a göre (2012) romantik acı, yirminci yüzyıl boyunca psikolojik bir söylem olarak ve dolayısıyla kusurlu ve zayıf bir benliğe atfedilebilen bedenin ve zihnin bir "düzensizliği" olarak sunulmuştur. Bu bakış açısını değiştirmek isteyen Illouz, aşk acısının kaynağını çocuklukta yaşanan yetersizlikler veya yetersiz farkındalıklardan toplum ve kültürün modern benlikleri ve kimlikleri yapılandırma biçimine kaydırmaya çalışmıştır. Bu yaklaşımı benimseyen Illouz, geç modernlikte romantik acının nedenlerini incelemek için argümanını bir dizi anahtar yapı etrafında yapılandırmaktadır.

Romantik acının kaynaklarından birisi çağdaş evlilik pazarıdır. Diğer dönemlerde ve diğer geleneklerde gerçekleşen evliliğin aksine Batı kapitalist toplumları, rekabetin daha yoğun ve daha genelleştiği ve seçimin en azından dışa dönük olduğu bir "kendi kendini düzenleyen karşılaşmalar piyasasıdır" (Illouz, 2007 s.41) ve kişisel zevk, fiziksel çekicilik ve kişilik gibi öznel faktörler tarafından yönetilir. Bu nedenle kişinin evlilik pazarında ne kadar iyi olduğu, kişinin cinsel pazarda ne kadar iyi olduğu ile bağlantılıdır.

Brucker da Illouz'un modern dünyada aşkın baş döndürücü bir boyuta ulaştığ1 söylemini desteklemektir. Brucker (2005, s.208) aşkı Batı'nın genel ideolojisi olarak tanımlamış ve aşkı boşuna ve gerçekçi olmayan beklentiler ile aşırı doldurulmuş olarak görmüştür. Kendisine verilen aşırı önemden ötürü sevgiye giden yol olmaktansa sevmek için bir araca 
dönüşür ve bu insanlık dişılığa yol açabilir (s.170). Dahası, aşk içimizde psikolojik köklenme yaratma gücüne sahipse, eşzamanlı olarak üzerimizde yıkım gücüne de sahiptir. Bu durumdan korkarız çünkü aşkın adaletsizlik ve zulüm içerdiğini bilir ve terk edilebildiğini deneyimleriz (s.255). Brucker'a (2005) göre insanların aşktan beklentisi çoktur ancak önemli olan beklentinin çok olması değil aşkın doğru bir şekilde anlaşılmamasıdır. Aşk bir paradokstur, tutarsız, belirsiz aynı anda hem asil hem aşağı, hem zarif hem acı verici olandır. Ancak aşk belirsiz olduğu için arzu edilendir. Belirsizlik ortadan kalkarsa büyü de ölür.

Âşıkların sevgilerinin zamansız ve sınırsız olduğuna dair öznel duygusuna rağmen, romantik aşkın bir geçmişi olduğu ve belirli bir kültürel bağlam içinde var olduğu aşikârdır. Çoğu teorisyen için bugünkü aşk anlayışımız, âşık olmanın merkezi olarak gördügümüz cinsel tutkunun bunun yerine genç bireyleri uygunsuz ve tehlikeli irtibatlara çekebilecek, düzenlenmiş evlilikleri çözebilecek ve anlatılmamış çatışma ve sefalete neden olabilecek tehlikeli bir zorlama olarak tasvir edildiği Avrupa modern öncesi kültürde gelişmiştir. Bu tehditlere karşı korunmak için çocuk yaşta nişanlanma, genç kızlara refakat eden yaşlı kadınlar, kurumsal fuhuş gibi mekanizmalar erotik arzuyu batırmak adına bilinçli olarak geliştirilmiştir. Birçok tarihçiye göre, başka bir bireye karşı yoğun bir erotik çekim, sevgilinin idealleşmesine dönüşmüş ve sadece geleneksel toplum sanayileşme ve yeni başlayan kapitalizm sonucunda parçalanmaya başladığında ilişki evliliğe bağlanmıştır. Eski düzenin çöküşü, daha önceki zamanların karakteristik grup yükümlülükleri ile birbirine bağlı olmayan yeni bir tür üreme biriminin ortaya çıkmasına karşılık gelmiştir. Gadlin'in (1977) de belirttiği gibi bugün anladığımız ve yaşadığımız şekli ile yakın ilişkiler on dokuzuncu yüzyılın ortalarında yaşamı iş ve ev arasında parçalanmaya başlamış burjuva bireyler ile birlikte oluşmaya başlamıştır.

\section{Geç Modern Dönem İlişkiler}

Yirminci yüzyılın ikinci yarısında ailenin toplum için işlevlerinde önemli bir erozyon meydana gelmiş ve toplumda kimlik kazanmak anlamında evliliğin öneminin arttı̆̆ı görülmüştür. Ailenin toplumun sosyal ve ekonomik yaşamı için önemi azaldıkça, evliliğin önceki dönemlerde 
içinde taşıdığı anlam ile olan ilgisi de azalmıştır. İçinde yaşanılan topluluk, aile veya ulusal köken gibi geleneksel kimlik bilgisi kaynaklarının aksine sanayi sonrası toplumlarda inşa edilen kimlik büyük ölçüde meta seçimleriyle oluşmaktadır (Shields, 1992). Düğünler ve çıkılan balayı tatilleri bugün her zamankinden daha büyük ve daha detaylıdır, ancak bu ritüelleri üreten toplumsal güçler değişmiştir. Geçmişteki topluluk çıkarları dügün ritüellerini körüklerken, bugün bu "gelenekler" için itici güç sağlayanlar, kişisel hayat hikâyesi ve inşa edilmiş kimlik için yapılan bireysel arayıştır (Bulcroft vd., 1997). Romantizmin gerçek olduğuna olan inanış devam etmekle birlikte, varlığının devamının sağlanması için çiftlerin metaların romantizmini inşa ettikleri ritüellerin somut ve devamlı hale getirilmesi, bu eylemin kimlik yapılanması ile birleştirilmesi, eksikliğinin de kişilerdeki çeşitli bozukluklardan kaynaklandığının desteklenmesi gerekmektedir.

Akrabalığın bozulması, kişinin statüsünün belirlenmesinde başarının artan önemi, kadınların evlilikte artan ekonomik bağımsızlı̆̆ı, aile ve ekonomik üretim işlevlerinin ayrılması ve hem sosyal hem de coğrafi hareketliliğin yüksek seviyeleri sebepleriyle evliliğin kişinin sosyal ve ekonomik statüsünün belirleyicisi olarak önemi, geç modern toplumda büyük ölçüde azalmıştır. İki gelirin birleşiminden hala bazı ekonomik avantajlar elde edilebilir, ancak çocukların artan ekonomik maliyetleri ve aile hayatının hareketlilik ve erken kariyer gelişimi üzerine getirebileceği kısıtlamalar, evliliği birçokları için tartışmalı bir ekonomik karar haline getirmektedir. Evliliğin azalan sosyal ve ekonomik önemi, artan birlikte yaşama, evlilik dışı doğum sayısı, evlilik yaşı ve 1967'den bu yana en düşük evlilik oranlarında görülebilir (U.S. Bureau of the Census, 1998). Toplumsal ve ekonomik önemindeki azalmaya rağmen evliliğin devam eden değerinin bir nedeni, bu dönemde samimi ilişkilerin ve evliliğin kazanmış olduğu kişisel önem olabilecek iken diğer bir neden aşkın ideolojik işlevinin de toplum ve bireyler üzerinde çağa ayak uydurarak var olmaya devam etmesi olarak düşünülebilir.

\section{Aşkın İdeolojileri}

Tüm aşk ideolojilerinin çıkış noktası sayılabilecek ideoloji Platon'un Sempozyumu'nda yer alan Aristophanes efsanesidir. Efsaneye göre, in- 
sanlar dört bacaklı, iki yüzlü bir şekilde yuvarlak yaratılmışlar ve üç farklı şekilde dünyaya gelmişlerdir. Birinci grup iki tarafı da erkek olan güneşin çocuğu, ikinci grup iki tarafı da kadın olan dünyanın çocuğu ve üçüncü grup hem erkek hem kadın olan Ay'ın çocuğudur. Yuvarlak bedenleri ile oradan oraya neşe içerisinde yuvarlanırken Zeus'un tapınağına tırmanmak istemeleri Zeus'u kızdırmış ve kılıcı ile bu iki kafalı ve dört bacaklı canlıları ortadan ikiye ayırmıştır. O günden beri de kendilerinin "diğer yarısı" eksik şekilde dünyanın etrafında dolaşarak diğer yarılarını aramaya koyulmuşlardır. Aristophanes birbirinden ayrı olan iki kişi birbirini tekrar bulduğunda, asla ayrılmak istemediklerini ve tekrar "bütün" hissetmek istediklerini iddia eder (192c). Hala Aristophanes efsanesinin büyüsü altında olmamız gerçekten şaşırtıcıdır: Her insan için yaratılmış onun mükemmel, eksiksiz yarısı, eşi dışarıda bir yerlerde onu arıyordur. Tek zorluk bu kişiyi bulmaktır ve bu bir kez gerçekleştiğinde sonsuz mutluluk ortaya çıkacak, her yarım tekrar bütün hissedecek ve zahmetsizce sonsuza dek mutlu yaşayacaktır. Dahası muhtemelen biri hemen diğer yarısını tanıyabilir, dolayısıyla "ilk görüşte aşk" ideolojisi ikinci ideoloji olarak karşımıza çıkar. Bu aşk anlayışı kolektif hayalimizin çoğuna nüfuz eder ve masallar ve diğer edebi ve sanatsal formlar gibi güçlü araçlarla sürdürülür.

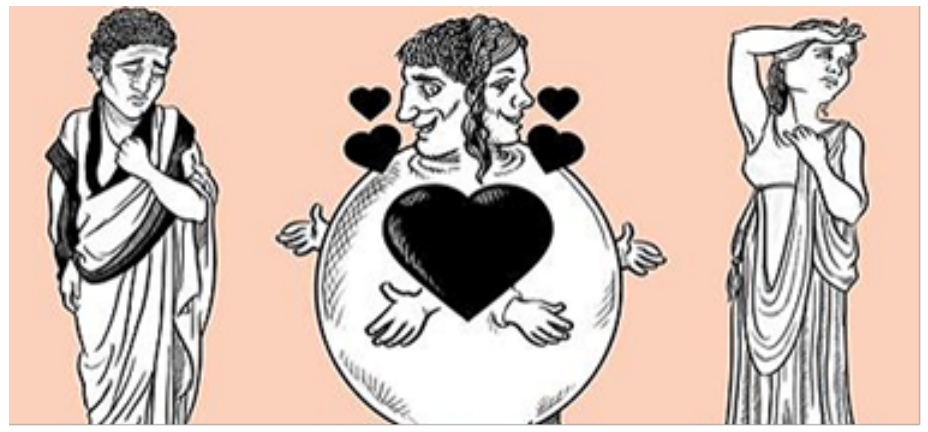

Şekil 1. Diğer yarıların arayan kadın ve erkekler. (Kaynak: youtube.com/watch?v=YDvMRvWjl9Q).

Bu mitin en iyi yanıtı, de Sousa'nın Rorty'den (1987) ödünç aldığı tarihi kavrama dayanan bir aşk anlayışıdır. De Sousa'ya (2015) göre aşk, iki kişi arasındaki uyum, birlikte paylaştıkları tarih ve karşılıklı şekillen- 
dirme sürecidir. Bir diğer efsane ise bir seferde sadece bir kişinin sevilebileceği Platonik efsanedir. Bu efsaneye göre ruh eşi vardır ve kişi evrende yalnızca tek bir doğru kişi ile eşleşir. Ruh eşini bulduğu anda ise büyük bir aydınlanma yaşar. Bu durum insanları en doğru partneri ya da diğer bir deyişle ruh eşlerini bulma konusunda sıklıkla ümitsizlik yaşamalarına neden olur. Aşkın beyin sistemini nasıl etkilediği üzerine çalışmalar yapan antropolog Helen Fischer' a (1994) göre bunun nedeni ise insanların romantik aşkın, beyin fonksiyonları ile ilişkili kimyaya dayalı bir gerçeklik olmasını reddetmelerinden kaynaklanır. Aşkın büyülü bir oluşum olmasına inanmak isteyen insanlar büyünün bozulmasından korktukları için aşkın doğaüstü olana ait olmasını isterler. Bu kişilere iyi ve özel hissettir.

Ortega y Gasset (2012) iki ruh arasındaki gerçek birleşmenin mistik deneyimlerle karşılaştırılabilir Tanrısal bir fenomen olduğunu, ayrıca bu benzerliğin kanıtının genellikle duygusal deneyimlerde kullanılan kelime dağarcığında yattığını düşünür. Mistik deneyimler erotik bir dille anlatılırken, âşık olma deneyimlerinin genellikle dini ifadelere dayanmasının sebebi de burada yatmaktadır. Bu Tanrısal ve mistik duyguya erişmek, hayat boyunca tek bir kez yakalanabilecek bir şans olduğunu düşünmek ve bu şansa ulaşmak için çaba sarf etmek aşk duygusunun evcilleştirilen tarafının toplumun kontrolü için kullanılabilen romantik aşk ideolojisine dönüştüğünü göstermektedir (Ben-Ze'ev, 2008, s.17).

Romantik aşk, başka bir kişiyle birleşmek isteme, cinsel cazibe ve diğerinin refahını koruma arzusu da dâhil olmak üzere, âşık olan insanlar arasında oluşan yoğun bağları ifade eder. Duygusal özelliklerine ek olarak, âşık olmak seks, susuzluk ve açlık kadar önemli olan temel bir itici güç olabilir (Aron, Fisher, Mashek, Strong, Li ve Brown, 2005). Birçok şiir, şarkı ve romanın üzerinde durduğu gibi, hayatta daha ödüllendirici birkaç şey vardır. Ancak aşk duygusunun aksine geleneksel romantik ideolojiler, sevginin nasıl ortaya çıkması ve canlandırılması gerektiğini belirleyen kuralcı kültürel senaryoları ifade eder. Bu senaryolar oldukça cinsiyetlidir çünkü her cinsiyetin üyelerinin sevgiyi nasıl göstermesi gerektiğini ayırt ederler, erkekler ve kadınlar için farklı "aşk rolleri" belirtirler. 
Geleneksel romantik ideolojiler, romantik aşkın kültürel algısını o kadar derinden etkilemiştir ki, birçok insan aşkı basit ve yürekten deneyimlemekte özgür değildir. Aksine aşkı belirli ve son derece cinsiyetli yollarla yaşamak zorunda olmanın sınırlılığını hissetmektedir. Geleneksel romantik ideolojiler insanların seçimlerini kısıtlayarak heteroseksüel romantik ilişkilerin kalitesini düşürebilecekleri gibi, cinsiyetler arasında tam eşitliğe ulaşmanın önündeki engel olarak da görülmektedirler. Toplumsal cinsiyet ilişkilerinin sosyal yapısal teorileri (Glick ve Fiske, 1999; Jackman, 1994; Ridgeway, 2001) nedeni ile kadınlar ve erkekler romantik roller hakkında gerçekçi olmayan kültürel idealleri yaşamak durumunda kalmaktadır.

Karşı cinsten kaçınarak ve akran ilişkilerinde farklı sosyal normlar geliştirerek geçirilen bir çocukluktan sonra, genç heteroseksüel ilişkilerinin yaşanması veya üzerine dahi konuşulması zor olmaktadır. Bazı kültürlerde, cinsel teması katı bir şekilde yasaklayan senaryolar, ailelerin ittifakına göre bireysel tercihlerden daha çok uygun evlilik ortakları seçen yetişkinler tarafından uygulanabilir (Kottak, 2004). Bununla birlikte, Batılı ülkelerde, yeni yetişen genç cinselliği sınırlı ebeveyn denetimine tabi olarak daha çok bireysel özgürlük meselesi haline gelmiştir (Giordano, 2003; Manning, Longmore ve Giordano, 2005). Yeni yetişen gençlerin potansiyel romantik partnerleri ile nasıl etkileşime girecekleri konusundaki beklentilerini bildiren kültürel normlar veya senaryolar oldukça güçlüdür. Ayrıca, bu tür metinlerin içeriği hala nispeten geleneksel cinsiyet normlarıyla tutarlıdır ve etkileşim stillerindeki cinsiyet farklılıklarını güçlendirir (Holland ve Eisenhart, 1990; Rose and Frieze, 1989, 1993).

Bugün genç bireyler arasındaki flörtleşme eskiye oranla daha farklı şekillerde yaşansa da araştırmalar hala erkek partnerin kadın partnere göre daha aktif bir rol üstlendiğini göstermektedir (Holland and Skinner, 1987; Rose and Frieze, 1989, 1993). Erkeğin çıkma teklifini etmesi, kızı alması, hesabı ödemesi ve evine güvenli bir şekilde teslim etmesi gerekir. Cinsel ilişkiyi ise erkek çocukların başlatması beklenir. Kısacası, kültürel ideal, erkeklerin aktif ve iddialı olması gereken ve yetişkin erkeğin koruyucu ve sağlayıcı rolünü üstlendiği cinsiyet şeması ile tutarlıdır. Şövalyelik, romantizmin ayrılmaz bir parçası olarak kabul edilir. Bunun- 
la birlikte, kızların daha pasif, kadınsı bir cinsiyet şemasına göre hareket etmesi beklenmektedir.

Kültürel senaryolar genç kadınlara, erkekleri cezbetmek için nasıl davranmaları gerektiği konusunda tavsiyelerde bulunur. $\mathrm{Bu}$ tavsiyeler "nefsine uy, hakkında bir şeyler bildiğini veya hakkında konuşmayı sevdiğini bildiğiniz konuları aç, onunla açıkça yüzleşme veya çok iddialı olma, şakalarına gül ve başarılarına hayran kal" şeklinde özetlenebilir. (Maccoby, 1998, s.196). Çocukluklarını erkeklerden kaçınarak kısa devreli erkek egemenliğinde geçirdikten sonra, genç kızların erkeklerin romantizmini teşvik etmek için "sorumluluk almasına" izin vermeleri beklenir. Geleneksel romantik ideolojiler, genç kız ve kadınların erkek romantik partnerler üzerinde doğrudan bir etki yaratmamaları gerektiğini göstermektedir.

Kadın partnerin daha ince ve dolaylı stratejiler kullanarak erkek partner üzerinde etki göstermesi beklenir. Kadınlar kolej yaşına geldiklerinde usulüne uygun olarak "romantizm eğitimi almışlardır" (Holland ve Eisenhart, 1990). Bugün bile, kadınlar kronik olarak yaşamdaki birincil hedeflerinin doğrudan ekonomik ödüller ve prestij aramak yerine bir eş bulmak ve bir aile yetiştirmek olduğu fikrine maruz kalırlar. The Rules gibi tavsiye kitapları, Cosmopolitan gibi dergiler ve Laura Schlessinger (Dr. Laura) gibi radyo yayıncıları feminizmin öldüğünü söylerler ve kadınların gerçekten yapması gerekenin bir erkeği nasıl bulacakları ve tutacaklarını bilmeleri gerektiğini salık verirler. Ancak aynı zamanda, kolejdeki kadınlar, genellikle aile desteğiyle, başarı odaklı, bağımsız ve kariyer odaklı olmak için güçlü bir şekilde motive edilirler. Bu rakip inançlar kadınlarda ruhsal çatışmalar yaratabilmektedir.

Kadınlar gibi, erkekler de romantik ideolojiler ve bağımsızlık arayışları arasında farklı şekillerde çatışma yaşarlar. Toplumsal olarak kadınlardan "her şeyin önüne aşkı koymaları" beklenirken, erkeklerin erkeksi özerklikten ziyade zayıflık ve bağımlılık belirtisi olarak görülen aşk meselesine çok fazla girmemeleri beklenmektedir. Sonuç olarak, güçlü sevgi ve bağlılık duyguları erkeklerin cinsiyet kimliklerini sorgulamalarına neden olabilmekte ve romantik aşkın temel olarak bir kadın duygusu olduğu klişesi erkekler âşık olduğunda sıkıntı ve utanç kaynağı olabilmektedir. Lanthimos'un yönettiği The Lobster filmi de aşkın insanların tercihine bırakılmamasının insanların duygularından 
çok daha önemli olduğu bir dünyada aşk ideolojilerinin nasıl absürtleştiğini distopik bir evrende irdelemeye ve doğal olan insan duygularını doğal olmayan ortamlar yaratarak sorgulamaya çalışmakta, aşkın biricikliği peşinde koşarken toplumun tüm bireylere yüklediği ortak aşk kurallarını benimseyen insanların kendilerinden vazgeçerek yaşamaya çalıştıkları ilişkilere odaklanmaktadır.

\section{The Lobster Filminde Aşkın Tasviri}

Tarihi bilinmeyen bir gelecekte aşk ilişkileri üzerine yazılmış bir deneme olarak okunabilecek The Lobster, Lanthimos'un izleyicileri aşka dair farklı bir bakış açısına davet ettiği seçimler üzerine kurulu bir filmdir. Hükümetin belirlediği bir çerçevede yaşanmasına izin verilen aşk duygusu, tüm insanların çift olarak var olmaları gerekliliğini savunurken, tek olmanın toplumda tedirginlik ve kargaşa yaratacağından korkulduğu için tek kalan insanların hayvan olarak vahşi doğada hayatlarına devam etmelerinin daha doğru olduğu görüşünün altını çizen bir distopyadır.

Filmin açılış sahnesinde David'in yatağın bir köşesinde sessiz ve mutsuz bir şekilde oturduğu ve karısının ondan ayrıldığını açılamasını pasif bir şekilde dinlediği görülür. Bir sonraki sahnede David yanında köpeği ile bir otele girer ve kendisi hakkında bir dizi kişisel soru cevaplar. Burası aynı zamanda seyircinin David'in yaşadığı ve yaşamak üzere olduğu dünyaların aşka bakış açısının da az çok anlaşıldığı noktadır. Eşinin kendisinden ayrılması üzerine yalnız kalan David, hükümetin uygun gördüğü bir otele yerleşerek kendisine tanınan kırk beş günlük sürede orada bulunan insanlar arasından uygun bir eş bularak çift olmalıdır. Eğer uygun bir eş bulamazsa tek başına insan olarak yaşamasına izin verilmeyecek, dönüşmek istediği uygun bir hayvana dönüştürülerek yaşamına hayvan olarak devam edecektir. Bu, yönetime göre üzülmeyi gerektiren bir durum değildir. Neticede hayvan olarak devam edeceği hayatta kendisine uygun bir eş bulması için ikinci bir şans verilmiş olacaktır. İnsani duyguların kaos içeren yönlerini kontrol etmeye adanmış kurumsallaşmış bir ortam olan otelde başarısız ve beceriksiz bulunan bu insanlara en basit şekilde anlatılan "ne nasıl yapılır" şovları düzenlenir. Bekâr olmanın ne kadar tehlikeli olabileceği, erkek ve kadınlar üzerinden farklı şovlarla anlatılır. Tek başına bir kadına bir erkek saldırabilir 
ancak ilişkisi olsa başına böyle bir olay gelmez. Yine, tek başına yemek yiyen bir erkek boğulabilir ancak yanında eşi olursa onu kurtarabilir.

Otelde geçirilecek ilk gün tek yaşamanın ne kadar zor olduğunun anlatılması için otele yerleşenlerin tek kolu kelepçe ile bağlanır. "Bir elin nesi var iki elin sesi var" deyiminin uygulaması olarak okunabilecek bu davranışı, mastürbasyon yapmanın yasak olması ve otel hizmetinden sorumlu genç bir kadının erkek müşterilerin müdahil olmasına asla izin verilmediği özendirici cinsel yaklaşım takip edecektir. Otele geldiği ilk gün iki erkek arkadaş edinen David, birbirine uyumlu çiftlerin aynı tür kusurlara sahip olması gerektiğini öğrenir. Bacağı topallayan bir erkek ancak başka topla bir kadınla eşleşebilir ya da aniden burnu kanayan bir kadına birliktelik teklif edecek erkeğin de aynı dertten mustarip olması gerekir. Aksi takdirde birlikte olamazlar çünkü onlar Aristophanes'in bahsettiği Zeus'un ortadan ayırdığı birbirini arayan ruh eşleri değillerdir. Otelin temsil ettiği ancak tüm evrenin aynı kuralların geçerli olmasına inandığı bu yerde gri alanlar yoktur. Kişi cinsel kimliğine hemen karar vermek zorundadır. Adına açılan dosyada tüm bilgileri kayıt altına alınacak David, genç yaşlarda eşcinsel bir ilişki yaşadığını, bu nedenle biseksüel olup olamayacağını düşünürken kayıt alan kişi David'e ya kadın ya erkek eş seçebileceğini söyler ve buna hemen karar vermesi gerektiği uyarısında bulunur. Ayak numarası, pantolon, gömlek ve kemer bedeninde olduğu gibi her bilgi net ve kesin olmalıdır. Burası uzlaşmacı bir toplum değildir. Her şey siyah beyaz olmalıdır; karakterler ya ilişkide ve mutludur ya da sefil bir durumda, yalnız ve şikâyet eder durumdadırlar.

Kırk beş gün içerisinde çift olmayı başaramazsa dönüştürülmek istediği hayvana da hemen karar vermek zorunda olan David bir 1stakoz olmayı tercih eder. Otel yönetimi bu karara oldukça şaşırır çünkü insanlar genelde ilk akla gelen hayvan olan köpek olmayı tercih ederler ve bu sebeple dünya köpeklerle doludur. David'in erkek kardeşi de çift olmayı başaramamış ve isteği üzerine bir köpeğe dönüştürülmüştür. O günden beri David ile birlikte yaşamaktadır. Hayvana dönüştürülen kişiler eğer aileleri isterse vahşi doğaya dönmektense onlarla birlikte yaşamaya devam edebilirler. David neden ıstakoz olmak istediğini, 1stakozların yüz seneye kadar yaşayabilmeleri, aristokrat gibi soylu olmaları ve yaşadıkları süre içinde üremeye her zaman devam edebilmeleri özelli- 
kleri ile açıklar. David, Otel'in onu sınırlama ve kontrol etme hakkını sorgulamaz, insanlığını kaybetme ihtimaline karşı endişelenmez. Aksine kabuklu bir deniz hayvanına dönüşerek cinsel yaşamını nasıl elinde tutabileceğini, Otel'in insanları bir kontrol listesine indirgemesinden daha önemli bulur. David'e yalnızca âşık olması gerektiği söylenir ancak duygular ile kimse ilgilenmez. Otel sakinlerinin tıpkı sosyal medya hesaplarında olduğu gibi ilişki durumunu belli etmesi, ilişkiye başladıklarını ve çok mutlu olduklarını doğrulamaları yeterlidir. David duyguları pek belli etmeyen neredeyse o dünyaya ait olmadığı düşünülebilecek bir karaktere sahiptir ancak sevmeye ve sevilmeye özlem duyduğu her halinden bellidir.

Lanthimos romantik aşkı aramanın aşk ideolojileri çerçevesinde ne denli vahşet ve dehşet dolu olduğunu absürt bir dille anlatırken, aynı zamanda günümüzde insanların partner bulmak için kullandıkları sosyal medya uygulamalarına da sinyal göndermektedir. Filmdeki Otel, en yaygın kullanılan flört bulma uygulaması Tinder ya da OkCupid dünyasının küçük bir yansıması gibidir. Yalnız ve eş arayan kişiler birbirlerine yaklaşır ancak çeşitli anlamsız sebepler ile sürekli reddedilir. Örneğin, çok güzel saçlı bir kadın David kel olmamasına rağmen bir gün kel olabilir öngörüsü üzerine insan olarak son günü olmasına rağmen David ile çift olmak istemez. Oteldeki konuklardan birisi kurda dönüştürülmüş annesini bulmak üzere hayvanat bahçesine gittiğinde bir kurt tarafından 1sırıldığ 1 için sakat kalmıştır ve topallar. Diğer bir erkek konuğun ise peltek konuşma problemi vardır. David ise köpeğe dönüştürülmüş kardeşi sebebiyle problem yaşamaktadır. Bu durumun, kendisinin sonunun da bir hayvana dönüşmek olacağını yansıladığını düşünmektedir. David, miyop olması ve gözlük takması konusunda takıntılıdır, bu sebeple karısı ondan ayrıldığını söylediğinde tek öğrenmek istediği şey birlikte olacağ1 erkeğin gözlük takıp takmadığı olur. Otelde konaklayan "misafirlerin" isimleri yoktur, onları tanımlayan kelimeler bile insanları bir şeylere indirger: Topallayan adam, burnu kanayan kadın gibi.

İlişki kurallarının kalın çizgilerle çizildiği bu yerde insanlar gözlerine kestirdikleri kişiler ile yakınlaşmak için gereken her şeyi yapmaya hazırlardır. Karakterler, David'in Kalpsiz Kadın'ı etkilemek için sosyopati hissetmesi de dâhil olmak üzere birbirleriyle bağlantı kurmak için sakatlıklar yapmaya başladığında film, başkalarını etkilemek için kendilerini 
yeniden yaratan insanların yalnız kalmamak adına verilen bu savaşta "her şeyi yapmak mubahtır" iddianamesine dönüşmektedir. Ancak, alaycı ve komik bir sembolizm olarak başlayan bu durum, yavaş yavaş filmi ele geçirmek için genişler. Film akıl dışı bir önerme ile başlamış gibi görünse de her bir fikir en grotesk aşırılığa çekilerek izleyiciye verilmeye devam eder.

Otel yaşamina ait unsurlar Margaret Atwood'un benzer şeklide acımasız alegorik ögeler ile dolu romanı The Handmaid's Tale'i (1985) anımsatır: Mastürbasyon yasaktır ve itaatsizlik edenler korkunç bir şekilde cezalandırılır. Otel personeli açık bir şekilde otel sakinlerini himayesi altına almıştır. Oteldeki konaklama çift olmayı öven aşağılayıcı, zorunlu ve garip sunumlar ile noktalanır. Lanthimos (Stegan Paper, 2015), filmi toplumun romantik eşleşmeleri doğalında varsayılan bir durum, bekâr olmayı ise yine doğalında hasarlı ve problemli olarak görme biçiminden ilham alarak yazdığını belirtmektedir. Tıpkı Atwood gibi Lanthimos da rahatsızlı̆̆ını, mevcut sosyal geleneklerin bireysel özgürlük ve insani duygular adına korkunç maliyetlerle uygulandığı bir distopyaya taşımaktadır. Ancak Atwood'un kitabı ve onu takip eden dizi uyarlaması, açıkça tecavüz ve zorla taşıyıcı anne olma durumundan yükselen, bir ülkenin yüzeyinin altında kaynayan öfke ve umutsuzluk ile ilgilidir. The Lobster filmindeki muhalefet ise daha incedir ve daha derinlere işleyen bir duruma gönderme yapar. The Lobster filminde umut, yaşamın bir parçası değildir.

The Lobster filminin sormaya çalıştığ soru kişilerin kendi istek ve arzularını mı yoksa toplumun kendilerinden beklediği normları mı ilişkilerinde yaşatmaya çalıştıklarıdır. Peki, bu durumda aşk bu ikilemin neresinde durmaktadır? Bekâr olmanın kişileri ikinci sınıf vatandaş durumuna soktuğu ve her durumda cezalandırmaya çalıştığı örneğinin tam karşısında çift olmaya savaş açmış ormanda bekâr şekilde yaşayan grup, bekâr olmaktan hoşlanan kişiler için bir cennet vaat ediyor gibi görünse de aynı katı kuralların işlediği bir başka cehennemdir. Kişilerin istedikleri şekilde bekâr ya da çift olamadıkları, birbirlerine sarılıp öpemedikleri ve duygularını özgürce paylaşmadıkları ilişki biçimleri tüm dünyayı sarmıştır.

David, filmin ikinci yarısına tekabül eden bu yeni dünyada bir kadına âşık olur. Ancak aralarındaki gizli bağı fark eden ormandaki hayatı 
yöneten kadın David'in âşık olduğu kadını şehre götürerek onu miyoptan kurtulma vaadi ile kandırıp gözlerini kör eder. Kaçma planları yapan David ve kör kadın şehirde birlikte yaşayabilmek için tüm benzer özelliklere sahip olmak zorunda olduklarından David de gözlerinden vazgeçme kararı alır. Bahns vd. nin (2015) yaptığı bir araştırmaya göre, ilişkilerin büyük bir kısmı ortak değer ve inançları paylaşmakta ve sahip oldukları ortak noktaları henüz ilk buluşmada keşfetmek durumundadırlar. Ancak filmdeki karakterler aniden kanayan burun gibi gerçek olamayacak derecede benzerlikler bulmaya çalışırlar. Lanthimos'un absürt örnekler ile konuya yaklaşması seyirciyi gülümsetse de toplumun ilişkiler konusunda insanlara dayattığı kurallar Lobster dünyasındakilerden çok uzakta değillerdir. Kişiler genellikle ilk buluşmalarında kendilerini daha çekici kılmak adına karşı tarafın hoşlanacağı davranışlara sahipmiş gibi yapabilmektedir. Bu örnekler filmde David'in zalim kadınlardan hoşlanır gibi yapması ya da topal kişinin aniden burnu kanıyor gibi davranması örnekleri ile yansıtılır.

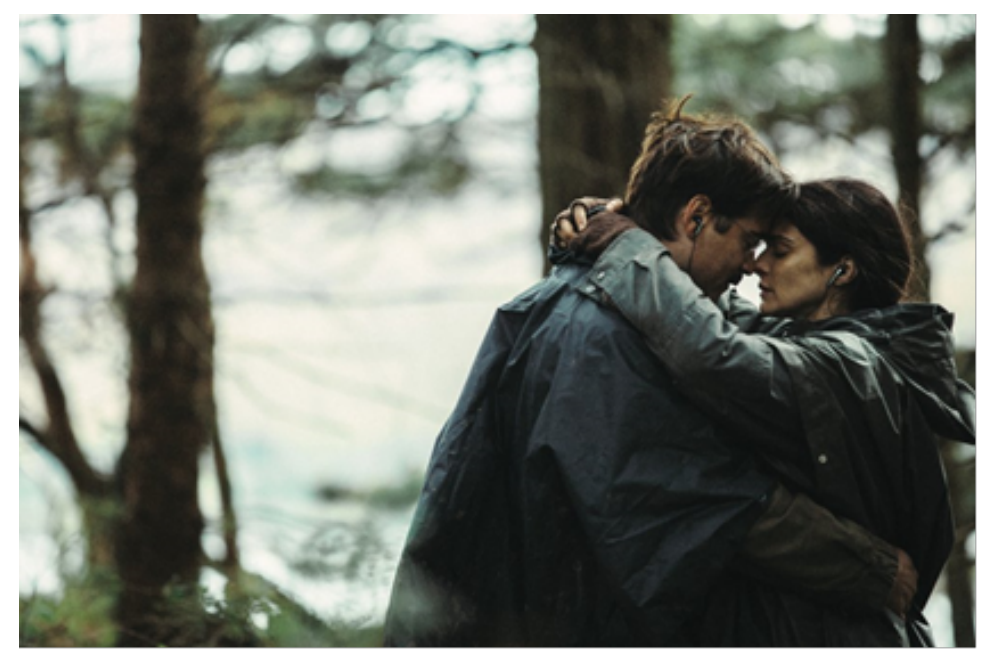

Şekil 2. Sevgiyle birbirine sarılmanin yasak, zor ve imkânsız olduğu yalnızlar ormanı (Kaynak, https://www.nytimes.com)

David'in Otel'deki zalim dünyadan ormana kaçarak orada özgür bir şekilde yaşayacağı düşüncesi, ormanda karşısına çıkan kurallar ile yıkılır. Grup halinde yaşayan ve kısıtlamalardan kaçarak kendilerine 
daha özgür bir dünya yaratmak isteyen gruplar arasında da kurallar baş gösterir ve her iki dünya da birbirinden daha az zalim değildir. Shelly O'Molly'e göre (2016) Lanthimos, filmlerinde insanların patolojik sistem ihtiyaçları ile ilgilenmektir. İnsanlar hayatlarının her anını çeşitli ögelere ayırarak kontrol etmeye çalıştıklarında totaliter bir hükümetin yukarıdan aşağı kurallar koymasına gerek kalmamaktadır. Kurallar çerçevesinde hayatına devam edemeyen birey, bir kanun kaçağı, bir muhalif, sistemin herkes için çalışmadığını hatırlatan ve hoş karşılanmayan birisi haline dönüşür. Bu nedenle, birbirlerine karşı alternatif olarak sunulan dünyaların her ikisinde de insanların kendilerine koydukları kurallar sebebiyle acı yaşanmaktadır. David, bu sistemde ayakta kalabilmek ve âşık olduğu kadın ile birlikte olabilmek için sistemden kaçmak yerine oyunu kuralları ile oynamaya karar verir.

\section{Sonuç}

Lanthimos'un 2016 yapımı The Lobster filmi, aşk, güç ve aşkın ideolojik gücü üzerine odaklanmış alegorik bir distopyadır. Bilimkurgunun romans alt türünü bünyesine dâhil etmiş olan film absürt ögelerden yararlanarak zaman zaman karanlık bir komediye de dönüşse, merkezine aldığı nokta modern dünyada aşka ve aşkın birlikte yaşanacak güzel bir duygu olmasına yabancılaşmadır. Lanthimos sinemasına özgü objektif bir kayıtsızlık ile seslendirilen film, baskıcı yönetim altında hayatın rahatsız edici atmosferini âşı olmak ve olmamak zorunlulukları üzerinden yansitmaktadir.

Modernitenin romantik kültürel çekirdeği olarak okunan aşk, toplumsal yapının bozulmasına kışkırtıcı bir şekilde sebebiyet veren ve bu nedenle sıkı bir şekilde denetlenmesi gereken eylemler arasında görülmektedir. Çift olmanın ve ilişki yaşamanın öneminin desteklendiği ve filmde Otel olarak resmedilen sistem, aşkın ideolojik boyutunu da desteklemekte, kontrol altında ve belirlenen kurallar çerçevesinde yaşanmasının herkesin yararına olduğu mesajını içermektedir. Kültürel senaryoların ilişkilerin içeriğini ve yaşanma biçimlerini tekdüzeleştirme çabası, The Lobster filminde uç örnekler üzerinden absürt bir şekilde 
yansıtılmış, birbirlerinin alternatifi olarak okunabilecek iki dünyanın varlığı da aşkın kurallardan kaçamayacağının altını çizmiştir.

Avrupa'da değişen romantizm ve aile politikaları karşısında çeşitli anlamlandırma süreçlerinden geçen aşk kavramı, yirmi birinci yüzyılda da farklı ideolojik yapılanmalar ile değişip dönüşmeye devam etmektedir. Aşkın Aristophanes efsanesine kadar uzanan geçmişi bugün geçerliliğini korumakla birlikte kültürel yapılanmanın evlilik ve ilişki biçimlerini ortak ekonomik bir potada birleştirme noktasından kendini var etme ve toplumda dışlanmama noktasına taşıması aşkın biricikliği peşinde koşan insanların toplumun aşk kavramına yüklediği ortak kurallara indirgenmesine sebebiyet vermektedir. Lanthimos'un film içerisinde sistemin karşısına yerleştirdiği isyancı grubun da insanların hayatını karartacak kadar aşk ve birlikteliğe karşı katı kurallar ile yürütülmesi, aşk konusunun özgür sanılan kısımda dahi ne kadar kontrol altında tutulduğunun altını çizmektedir. Sonuç olarak denilebilir ki, aşkın gözü kördür deyimi, bireylerin hissettikleri duyguları yaşamak adına kabul etmeyi göze aldıkları ideolojik yapılanmanın altını çizmekte, David'in filmin sonunda gözlerini kendi elleri ile kör etmesi bu soyut algıyı somut bir gerçekliğe dönüştürmektedir. 
EXTENDED ABSTRACT

\title{
The Dark Aspects of Modern Relationships: Romantic Ideology in The Lobster \\ *
}

\author{
Selen Gökçem Akyıldız \\ Niğde Ömer Halisdemir University
}

Dystopian movie The Lobster can be read as the last leg of a process in which a system that will allow love to exist in a relationship but in a controlled manner due to its non-appropriate matchmaking, rule-breaking and social norms-changing structure, has been destroyed and restructured for centuries. The film depicts a black and white world that is hidden behind a timeless future, but is surrounded by rules in today's world, has lost its organic structure. The Lobster emphasizes the point that love has reached in the modern world and how the general rules, which are tried to be loaded on the feeling of love full of rules that can only be achieved if fairy tales are believed, lead people to an unhappy dead end.

Historically, love, a concept that has been theorized in various ways, has undergone various processes of signification in the face of changing romanticism and family politics in Europe. Love, which is one of the most attractive driving forces in human life (Irigaray, 1993) has been seen as a psychic, immeasurable and rebellious subject, predicted by art, literature and philosophy, in other words, a field that is not wanted to be taken into the field of science, but is increasingly emphasized as an element of pleasure. Early European family history helped establish love as a source of security in the social realm, while developing the contradictory and politically inconsistent meanings of love laws based on various traditions. In European middle and upper class socialism of the nineteenth and early twentieth centuries, love emerges as a narcissistic, spontaneous orientation towards individual desires and anxieties of existential nature (Kierkegaard 1847, Heidegger 1927, Freud 1953-74). In the second half of the twentieth century, increasingly multicultural and equally individualistic ideas of romanticism began to emerge on the ba- 
sis of freedom, choice, and rationality that replaced religious and moral traditions (Giddens 1992).

In the second half of the twentieth century, an important erosion occurred in the functions of the family for the society and it was seen that the importance of marriage in terms of gaining identity in the society increased. As the importance of the family for the social and economic life of the society decreased, its relevance to the meaning of marriage in previous periods decreased. Contrary to traditional sources of identity information such as community, family or national origin, identity constructed in post-industrial societies is largely formed by commodity choices (Shields, 1992). Weddings and honeymoons are larger and more elaborate than ever before, but the social forces that produced these rituals have changed. While community interests fueled wedding rituals in the past, it is the personal life story and the individual quest for constructed identity that drives these "traditions" today (Bulcroft et al., 1997). Although the belief that romance is real continues, in order to ensure the continuation of its existence, the rituals in which the couples build the romance of commodities should be made concrete and continuous, this action should be combined with identity construction, and it should be supported that its deficiency is caused by various disorders in people.

Like women, men experience conflict in different ways between romantic ideologies and their quest for independence. Socially, women are expected to "put love before everything else," while men are expected not to get too involved in love, which is seen as a sign of weakness and dependence rather than masculine autonomy. As a result, strong feelings of love and commitment can cause men to question their gender identity, and the stereotype that romantic love is basically a female emotion can be a source of distress and embarrassment when men fall in love. The Lobster movie directed by Lanthimos tries to examine how the ideologies of love become absurd in a world where love is more important than people's feelings, and to question natural human emotions by creating unnatural environments. It focuses on the relationships that people who adopt the common love rules they impose and try to live by giving up on themselves. The Lobster, which can be read as an essay on love relationships in an unknown future, is a film based on choices in which Lanthi- 
mos invites the audience to a different perspective on love. The film is a dystopia that underlines the view that it is better for people who are left alone to continue their lives in the wild as animals, as it is feared that being single will create uneasiness and turmoil in the society, while defending the feeling of love allowed to be lived in a framework determined by the government, the necessity of all people to exist as couples. In this place where the relationship rules are drawn with thick lines, people are ready to do whatever it takes to get close to the people they catch their eye. When the characters begin to suffer disabilities to connect with each other, including David's feeling of sociopathy to impress The Heartless Woman, the movie turns into an indictment that "anything is okay" in this war of being alone with people reinventing themselves to impress others. However, what started out as sarcastic and funny symbolism slowly expands to take over the movie.

Although the movie seems to start with an irrational proposition, each idea continues to be given to the audience by being pulled to the most grotesque extreme. The question that Lobster tries to ask is whether people try to keep their wishes and desires alive or the norms that society expects from them in their relationships. So, where does love stand in this dilemma? In the face of the example that being single makes people become second-class citizens and tries to punish them in every situation, the group living in the woods, who have declared war on being a couple, seems to promise a paradise for those who like to be single, but it is another hell where the same strict rules operate. Relationship styles in which people cannot be single or couple as they wish, hug and kiss each other and share their feelings freely have surrounded the whole world. To conclude it can be said that Lanthimos' 2016 film The Lobster is an allegorical dystopia focused on love, power and the ideological power of love. Even if the movie, which has incorporated the romance subgenre of science fiction, turns into a dark comedy from time to time by making use of absurd elements, the point it focuses on is alienation from love and its being a beautiful feeling to live together in the modern world. The film, which is performed with an objective indifference peculiar to Lanthimos cinema, reflects the disturbing atmosphere of life under oppressive management through the necessity of falling in love and not being in love. 


\section{Kaynakça / References}

Aron, A., Fisher, H.., Mashek, D., Strong G., Li H., Brown, L.L. (2005). Reward motivation and emotion systems associated with early-stage intense romantic love. Journal of Neurophysiol, 94, 327-337.

Atwood, M. (1985). The handmaid's tale. Anchor Books.

Bahns, A., Crandall, C., Preacher, K. (2005). Similarity in relationships as Niche construction: Choice, stability and influence within Dyads in a free choice environment Journal of Personality and Social Psychology. https://www.apa.org/pubs/journals/psp/ 112 (2), 329-355.

Beck, U., Beck-Gernsherim, E. (1995). The normal chaos of love. (Çev. Mark Ritter ve Jane Wiebel). Polity Press.

Ben-Ze'ev, A. (2008). In the name of love: Romantic ideology and its victims. Oxford Scholarship Online.

Berger, P., Berger, B., Kellner, H. (1973). The homeless mind. New York: Random House.

Brucker, G. (2005). Giovanni and lusanna: Love and marriage in renaissance Florence. University of California Press.

Bulcroft, K., Bulcroft, R., Smeins, L., Cranage, H. (1997). The social construction of the north american honeymoon, 1880-1995." Journal of Family History 22 (4), 462-490.

Buttler, J. (1997). Excitable speech: a politics of the performative. Psychology Press.

Cancian, F. (1986). The feminization of love. Signs, 11(4), 692-709.

Cole F.L. (1988) Content analysis: Process and application. Clinical Nurse Specialist, 2(1), 53-57.

De Sousa, R. (2015). Love: A very short introduction. Oxford University Press, New York.

Dowd, J.T., Pallotta, N.R. (2000). The end of romance: The demystification of love in the postmodern age. Sociological Perspectives, 43(4), 549-580.

Fein, E., Schneider, S. (1995). The Rules: Time-tested secrets for capturing the heart of Mr. Right. New York: Warner Books.

Fein, E., Schneider, S., Schneider, H. (1997). The rules II: More rules to live and love by. New York: Warner Books.

Fischer, H. (2004). Why we love: The nature and the chemistry of romantic love. New York, NY: Henry Holt.

Foucault, M. (1980). “The confession of the flesh," in Michel Foucault: Power/Knowledge, ed. Colin Gordon (Hemel Hempstead, UK: Harvester. 
Foucault, M. (1988). "Technologies of the self," in Technologies of the self, ed. L. H. Martin et al. London: Tavistock.

Gadlin, H. (1977). Private lives and public order: A critical review of the history of intimate relations in the united states. G. Levinger, H.L. Raush (Eds). Close relationships: perspectives on the meaning of intimacy s. 33-72 Amhert: University of Massachusetts Press.

Gasset, O.J. (2012). On love: aspects of a single theme. Martino Fine Books.

Giddens, A. (1992). The transformation of intimacy: sexuality, love and eroticism in modern societies. Stanford University Press.

Giordano, P. C. (2003). Relationships in adolescence. Annual Review of Sociology, 29, 257-281.

Giordano, P.C, Longmore, M. A. ve Manning, W.D. (2005). Gender and the meanings of adolescent romantic relationships: a focus on boys. American Sociological Review, 71(2), 260-287.

Glick, P. ve Fiske, S. (2006). The ambivalence toward men inventory: differentiating hostile and benevolent beliefs about men. Psychology of Women Quarterly, 23( 3), 519-536.

Goode, W. T. (1959). The theoretical importance of love. American Sociological Review, 24(1), 38-47.

Habermas, J. (1971). Toward a rational society: student protest, science and politics. Beacon Press.

Heidegger, M. (2008). Being and time (Harper perennial modern thought). Harper Perennial Modern Classics; Reprint Edition.

Holland, D.C ve Eisenhart, M.A. (1990). Educated in romance: women, achievement and college culture. University of Chicago Press.

Hsieh, H. F., and Shannon, S. E. (2005). Three approaches to qualitative content analysis. Qualitative Health Research, 15(9), 1277-1288.

Illouz, E. (1997). Consuming the romantic utopia: love and the cultural contradictions of capitalism. Berkeley University Press.

Illouz, E. (2007) Cold intimacies: the making of emotional capitalism. Polity Press, London.

Illouz, E. (2012). Why love hurts: a sociological explanation of polity. Polity Press, Berlin.

Irigaray, L. (1993). Je, tu, nouns: toward a culture of difference. (Çev. Alison Martin). New York, London: Routledge.

Jackman, M. (1994). The velvet glove: paternalism and conflict in gender, class and race relations. University of California Press. 
Kierkegaard, (2013). Master Kierkegaard: The complete journals: summer 1847, fal/winter/spring 1847-1848, and summer 1848. Cascade Books.

Kottak, C.P. (2004). Cultural anthropology. McGraw-Hill.

Lasch, C. (1995). Haven in a heartless world: the family besieged. W.W. Norton and Company.

Lynch K. (2009) Affective equality. love, care and injustice. Palgrave Macmillan.

Maccoby, E.E. (1998). Family and public policy. The two sexes: Growing up apart, coming together. Belknap Press/Harvard University Press.

O'Molly, S. (2016). The Lobster. 20.09.2020 tarihinde https://www.rogerebert.com/reviews/the-lobster-2016 adresinden erişildi.

Paper, S. (2015). Writer/ director yorgos lanthimos exclusive interview-The Lobster. https://www.youtube.com/watch?v=2VsWWP4S-ZA

Parsons, T. (1951). The social system. Glencoe, IL: Free Press.

Plato (2003). The symposium. Penguin Classics; Revised ed. Edition.

Ridgeway, C. (2011). Framed by gender: how gender inequality persists in the modern world. Oxford University Press.

Rorty, A.O. (1987). The historicity of psychological attitudes: love is not love when alters not when it alteration finds. Midwest Studies in Philosophy, 10(1), 399-412.

Rose, S.M. ve Frieze, I.H. (1993). Young singles' scripts for a first date. Gender and Society, 3(2), 258-268.

Shields, R. (1992). Lifestyle shopping: the subject of consumption. New York: Routledge.

Szachowicz-Sempruch, J. (2015). Constructing family, understanding love: The precariousness of bonding and romance in Europe. Ed. Eszter Kovats. Love and Politics. Friedrich-Ebert Stiftung.

U.S. bureau of the census, statistical abstract of the united states. (1998), 118th ed. Washington, DC: U.S.

Weber, M. (1958). The protestant ethic and the spirit of capitalism. New York: Scribner.

Weber. M. (1968). Economy and society. Totowa, NJ: Bedminster.

White, M.D. ve Marsh, E.E. (2006). Content analysis: A flexible methodology. Library Trends, 55(1), 22-45. 


\section{Kaynakça Bilgisi / Citation Information}

Gökçem Akyıldız, S. (2021). Modern ilişkilerin karanlık vehçeleri: the lobster filminde romantik ideoloji. OPUS-Uluslararası Toplum Araştırmaları Dergisi, 17(38), 5631-5656. DOI: 10.26466/opus. 807052 